\title{
先锋小说对传统文学家族题材的继承与改造
}

邱丹 ${ }^{1}$ 邱菊 2

1 长春工程学院 2 昌图县第四高级中学

DOI:10.32629/er.v3i5.2704

[摘 要] 中国作家对家族题材小说的创作一直持有创作热情,家族叙事也构成了中国传统文学重要的叙事主题。先锋小说在反叛传统文学的过 程中,也呈现对传统文学题材的继承与拓新,其对传统家族题材小说的改造与有效转化,形成了独特的审美韵味。

[关键词] 先锋小说; 家族题材; 继承改造

最初的家族叙事受史传传统影响较大。司马迁《史记》的 “本纪” 和 “世家”包含了大量帝王家族和世卿家族的史传书写, 后来的《左传》 也建立了以家族为中心的贵族世家体系, 这两部史传从某种程度上说开 创了家族叙事的先河。宋元以来涌现了大量的英雄传奇, 充分地体现了 家族建功立业的爱国情怀。不同于英雄传奇对家族题材的宏大建构, 以 《金瓶梅》与 《红楼梦》为代表的明清时期的家族小说将笔触伸向了家 族内部的世情生活, 内及日常, 外涉社会。及至五四以来的现当代作家, 也对家族题材的小说写作倾注了极大热情。譬如, 巴金的《家》、曹禺的 《雷雨》、林语堂的《京华烟云》、老舍的《四世同堂》、张爱玲的《金 锁记》、路翎的《财主底儿女们》、梁斌的《红旗谱》、欧阳山的《三家 巷》、王蒙的《活动变人形》、张炜的《古船》、陈忠实的《白鹿原》、王 安忆的《小鲍庄》、阿来的《尘埃落定》等, 他们以家族叙事为轴心, 家 族不同人物的命运、整个家族的兴衰由此成为社会发展变迁的一个缩 影。而且, 这些作品也体现了不同时代的作家对家族、历史、社会的深 入思考。二十世纪八十年代中后期, 先锋作家掀起了一场带有形式变革 的叙事革命。而家族叙事仍然是先锋作家热衷的题材, 先锋小说充分体 现了对家族叙事的继承与创新。

\section{1 家族的命运仍以人物的命运起伏为走向}

“家族小说” 是以家族叙事为核心的小说类型, 人物的命运线索构 成了叙事的核心, 这是传统文学中家族题材小说的鲜明特征。这一点, 在 先锋小说中得到了继承。但在先锋小说中, 人物的神圣光环被消解, 人物 的主观体验与情绪代替了复杂的情节支撑叙事。在传统的家族文化中, 家谱代表着以同宗共祖的血缘关系构建的世系延续体系, 具有一定的权 威性, 唯有男性能够进入家谱, 香火延续也是家族的延续, 生殖力也是生 命力的象征。在苏童的《罂粟之家》中, 刘氏家谱上的男性相继死亡, 则 意味着刘家的颓败与灭亡。刘老侠 “血气旺极而乱”, 他的前四个儿子 畸形早天, 家谱上的第五个儿子演义还是一个白痴, 他是刘老侠与刘家 老太爷的姨太太翠花花所生, 而沉草又是翠花花与长工陈茂所生, “血乱 没有好子孙”, “世代单传的好气血到沉草一代就杂了。杂了就败了, 这 是遗传的规律” “刘家子孙生命的退化与家族血脉的混杂就是家族走 向毁灭的征兆。饥饿、暴力、白痴是演义的抽象符号, 脏脏、溃烂、梅 毒是刘老信的抽象代码, 自私、贪婪、残酷是刘老侠的抽象表征, 白痴演 义被沉草杀死、刘老信与刘老侠分别死于两场大火、沉草用枪杀死了陈 茂, “一九五 $\bigcirc$ 年冬天, 工作队长庐方奉命镇压地主的儿子刘沉草, 至此, 枫杨树刘家最后一个成员灭亡。(2) 可见, 人物的最终命运就是家族的命 运。《一九三四的逃亡》, 祖母蒋氏与祖父陈宝年的七个子女都惨遭厄运, 蒋氏对最后一个孩子的追踪被长江隔绝, 当蒋氏的红桥抬进陈文治的家 中时, 她从家史中抹去, 一九三四年的年底祖父陈宝年 “紧握祖传的大头 竹刀” 就此丧命, 陈记竹器就此换代, 陈氏家族就此灭亡。家族的结局伴
随着人物的悲剧命运走向了颓败与没落。

\section{2 家族叙事仍触及伦理、人性、欲望等母题}

在传统文学的家族叙事中, 伦理、人性、欲望是其母题, 这在先锋小说 中得到了有效的继承。但先锋小说弱化了主题涉及的社会功能与意义, 强 化了人性暗处与生存本能的毁灭力量, 人性的衰败与性的衰败构成了生存 的颓败, 它们造成了家族不可挽回的颓败与毁灭。首先, 人性的丑婳。叶兆 言的《半边营》里, 男性的家族权威被女性所取代, 华夫人就像张爱玲笔下 的 “曹七巧” 一样处处呈现着对亲情的虐杀, 她逼死丈夫、害死儿媳、阻 碍大姐出嫁、甚至让儿子成为一个心理上的低能儿, 作者将笔触伸向了人 性的暗处。在《妻妾成群》中, 与对封建家族残害生命的罪恶制度的批判 相比, 苏童将着力点放在了对颂莲狭窄窒息的生存境遇的呈现上, 那种人 性沉沦带来的精神崩溃与家族腐朽造成的颓废气息共同构成了生存的景 观。苏童的《䍃粟之家》, 刘老侠冷酷地拒绝了女儿刘素子的求助, 最后将 女儿交给土匪姜龙, 刘素子以失身的三天三夜换取了刘家大宅的安稳。余 华的《在细雨中呼喊》就像一本记忆之书, 弟弟救人落水丧命, 父亲不仅没 有丧子之痛, 反而以此向政府邀功, 并沉浸在无差耻的性欲之中。在格非的 《敌人》中, 家族的毁灭源自血亲的自戨, 人伦亲情被血亲谋杀取缔, 恐惧 与孤独占满内心。在赵龙的记忆中, “父亲像是对沉默上了瘾, 在他那两片 薄薄的嘴唇中似乎隐藏了无尽的心思”。赵虎每次独自面对赵少忠的时 候, “总感到一种莫名其妙的紧张, 尤其是沉默不语的时候, 他更是手足 无措” 『。家族血亲传承的纽带被自我斩断。其次, “欲望” 的紊乱与罪 恶。苏童的家族小说的人物无不奔涌着肆意生长的欲望, 家族的支撑点发 生了变化, 靠血缘支撑的家族被欲望的罪踤所取代。《罂粟之家》中, 染上 梅毒大疮的刘老信用身上腐烂的脓血画押, 并在妓院完成了他与刘老侠的 最后一笔交易。沉草是陈茂与翠花花通奸的产物, 沉草的诞生不仅预示着 刘老侠的衰亡, 也是刘家走向崩溃消亡的结果。陈茂剥夺了沉草的 “姐姐” 的贞洁, 沉草扣动扳机将其打死, 性欲的错位造成了自我的毁灭。《一九三 四年的逃亡》里面, 那个集聚着少男少女精血的白玉瓷罐, 欲望能力的衰竭 也意味着家族的衰败。《米》的五龙, 性欲中黏着内心深处的悲琐、残忍与 变态, 他与织云私通、强迫绮云、游离于妓女之间, 最终带着身上的梅毒与 腐臭走向生命的毁灭。在先锋作家的家族小说中, 人性、欲望并不为社会 主题服务, 它们本身就构成了存在的主题。

\section{3 家族的历史与历史中的家族仍紧密相连}

在传统文学的家族题材中, 家族叙事往往与历史联系密切, 家族的 历史与历史中的家族形成了某种默契的暗合。在先锋小说中家族依然保 持着与历史的紧密关系, 但是构成历史真相的不是正义、革命与理性, 也 不是面向历史的宏大叙事, 历史充满了性、罪蒘与死亡, 每个人都参与着 历史的建构, 也在促成着历史的毁灭。先锋作家热衷家族叙事, 与他们避 让现实、规避社会意识形态的创作心理有关。压抑已久的话语欲望在“历 
史颓败” 的情境中找到了理想的阵地。与传统历史小说相同的是家族历 史的演进随着人物的命运发展轨迹而不断推进, 个人的历史也构成了家 族的历史。譬如《罂栗之家》沉草的一生虽然短暂, 他走完了从出生到 死亡的生命历程, 也在其生命历程中演绎了这个家族的由盛转衰的运动 轨迹; 《一九三四的逃亡》与《米》, 陈宝年、五龙的一生也是其逃亡一 一欲望一一还乡 (死亡) 的生命旅程, 伴随着他们生命的终结, 两个家族 都走向了难以挽回的历史悲剧。但与传统家族小说不同的是先锋作家不 再将叙事的重心放在还原历史的真相上面, 先锋作家感受到“一种对 “历 史” 的阉割与补充的双重快感” (1) 先锋作家凭借记忆进入历史, 并以 “死 亡” 结构历史, “死亡” 构成了推动历史故事前进的重要环节, 并构成故 事的高潮结局。历史的英雄形象演变成了人的萎缩, 历史被想象的碎片 阉割。譬如, 余华的《在细雨中呼喊》。而格非将历史设置成无数的空缺, 构成了不在的 “存在”, 也许这才是历史真正的样貌。譬如, 《青黄》寻 找的是九姓渔户残缺不全的历史。

\section{4 家族仍以一定的 “时间长度” 展演家族的兴衰消长}

在传统文学的家族题材小说中, 家族的世俗生活与生存景观辐射着社 会、历史的图景, 并呈现了历史的顺时性演进。在先锋小说中, 家族题材的 小说历史的时间性并未彻底消失, 仍以一定的历史时间演绎着家族的兴衰 与消长。但先锋小说, 家族永远无法排除命运的转机, 家族看不到任何生长 的希望, “家族” 的困境成为一种寓言性的象征, 它指向人类整体的生存本 相与生存困境。虽然先锋小说在叙事上消解了 “大写的人”, 但在家族叙 事中并没有将人彻底从历史中抹去, 人物仍然与历史相关, 先锋作家注重 人的日常性与世俗性的表达, 并通过透视这些人的生存境遇与生存本相来 展示人类历史发展过程中人类的心灵史、伦理道德史。在苏童的家族小说 中, 家族兴衰的历史脉络还是能够清晰可见的, 譬如《罂粟之家》中出现的 三个时间分别是 “一九三 $\mathrm{O}$ 年的刘家大院” 饥饿使演义变得暴躁, “一九

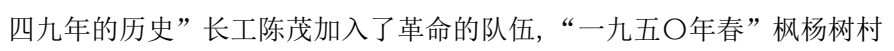
三千多人参加了地主刘老侠的批斗会, “一九五 $\bigcirc$ 年冬” 枫杨树村刘家最 后一名成员沉草死于工作组长庐方的枪声之中。这四个历史时间有条不紊 的穿插在家族的叙事之中, 构成了叙事的顺序, 同时也展演了一部家族生
存的历史, 即使这种历史观带有颓废的色彩, 但是历史行进的痕迹依然依 稀可见。

格非在谈论中国小说的 “两个传统” 时说: “一个不容忽视的现象 是, 近现代以来的小说对古典小说不同文类的重新书写和择取从未中 断。” 先锋小说在反叛与革新传统文学的同时, 也完成了对传统文学的 继承与创造性改造。

注释:

(1)苏童.罂栗之家 $[M]$.上海:上海文艺出版社,2004:49.

(2)苏童.罂栗之家[M].上海:上海文艺出版社,2004:62.

(3)格非.敌人[M].上海:上海文艺出版社,2013:23.

(4)陈晓明.无边的挑战一一国先锋文学的后现代性[M]. 北京: 中国人民文学出 版社,2015:231.

(5)格非.迷舟[M].广州:花城出版社,2013:176.

[参考文献]

[1]陈文新.传统小说与小说传统 [M].武汉:武汉大学出版社,2007:8.

[2]陈晓明.无边的挑战一一中国先锋文学的后现代性 [M]. 北京: 中国 人民文学出版社,2015:7.

[3]苏童.罂栗之家 $[M]$.上海: 上海文艺出版社,2004:8.

[4]苏童.一九三四年的逃亡 $[M]$. 上海: 上海社会科学院出版社, 1988:9.

[5]格非.敌人[M].上海:上海文艺出版社,2013:1.

[6]马原.马原文集[M].北京:作家出版社,1997:3.

[7]余华.余华文集[M].北京:作家出版社,2012:9.

[8]鲁定元.文学教育论[M].武汉:湖北人民出版社,2006:12.

[9]陈平原.六说文学教育 [M].北京:东方出版社,2016:8.

\section{作者简介:}

邱丹(1987--), 女, 汉族, 辽宁昌图人, 讲师, 文学博士, 长春工程学院, 研究方向: 中国现当代文学与文学教育。

邱菊(1980--), 女, 汉族, 辽宁昌图人, 昌图县第四高级中学, 语文教 研室教师,研究方向: 中国当代文学与语文教育。 